\title{
Regioselective enzymatic acylation of vicinal diols of steroids
}

\author{
M. Manuel Cruz Silva, ${ }^{a}$ Sergio Riva ${ }^{\mathrm{b}}$ and M. Luisa Sá e Melo ${ }^{\mathrm{a}, *}$ \\ ${ }^{a}$ Centro de Estudos Farmacêuticos, Lab. Química Farmacêutica, Faculdade de Farmácia, Universidade de Coimbra, \\ Rua do Norte 3000-295 Coimbra, Portugal \\ bistituto di Chimica del Riconoscimento Molecolare, C.N.R., Via Mario Bianco 9, 20131 Milano, Italy
}

Received 28 October 2004; revised 29 November 2004; accepted 25 January 2005

\begin{abstract}
Monoacylated derivatives of a complete set of 2,3- and 3,4-vicinal diols of steroids were prepared by regioselective lipasecatalysed transesterification reactions. The enzymes displayed different selectivities towards the vicinal diols depending on the configuration of the hydroxyl groups.

(C) 2005 Elsevier Ltd. All rights reserved.
\end{abstract}

\section{Introduction}

Polyhydroxylated steroids bearing vicinal diols on the A-ring are frequently found in Nature and some of them have relevant biological activities. For instance, the transdiaxial $2 \beta, 3 \alpha$-di-hydroxy pattern is present in natural sulphated sterols with antiviral ${ }^{1}$ or anti-angiogenic ${ }^{2}$ action, while $2 \alpha, 3 \alpha$-diols isolated from marine sources hold cytotoxic activity. ${ }^{3}$ Steroidal saponins displaying transdiequatorial $2 \alpha, 3 \beta$-vicinal diols are quite frequent as gitogenin derivatives with antitumor properties. ${ }^{4}$ In turn, the $3 \beta, 4 \beta$-diol functionality is present in a variety of steroids like in the agosterols, which induce reversal of multidrug resistance $^{5}$ and proteasome inhibition, ${ }^{6}$ as well as in formestane metabolites ${ }^{7}$ and in volkendousins, which are potent antitumor agents. ${ }^{8}$ Finally, the $3 \alpha, 4 \beta$-vicinal diol pattern has been identified in contignasterol, a natural antiinflammatory compound ${ }^{9}$ and, recently, in a steroid possessing chemotaxis activity. ${ }^{10}$

The discovery that lipases and proteases are able to act in organic solvents opened the way to an intensive synthetic exploitation of these biocatalysts, which, as shown in hundreds of papers and several industrial applications, display remarkable chemo-, regio- and stereoselectivity. ${ }^{11}$

Specifically in the steroids field, enzyme catalysis can play an important role for the mild and selective interconversion of functional groups via regioselective transformations. ${ }^{12-19}$

Keywords: Lipases; Steroids; Diols; Regioselectivity; Enzymatic esterification.

* Corresponding author. Tel.: +351 239 859990; fax: +351 239 827030; e-mail: samelo@ci.uc.pt
Studies on the transesterification of polyfunctionalyzed steroids have shown that hydrolases can have access to substituents either on the A-ring or on the D-ring and/or on the side-chain of steroids. Several lipases showed a preference for C-3 hydroxyl groups, ${ }^{13,14}$ whereas the protease subtilisin Carlsberg catalysed the acylation of C-17 OH. ${ }^{14}$ Moreover, stereoselective resolutions of epimeric alcohols located on the steroid side-chain have been carried out by lipase PS $^{15}$ and, more recently, by subtilisin. ${ }^{16}$

Concerning the modifications of A-ring substituents, the selectivity of lipases for 3-hydroxysteroids has been applied to the chemoenzymatic synthesis of pharmacologically relevant tibolone metabolites. ${ }^{17}$ Quite recently, we have reported a highly selective lipase-catalysed preparation of epimerically pure $5 \alpha, 6 \alpha$ - and $5 \beta, 6 \beta$-epoxysteroids through acylation or deacylation reactions at the $\mathrm{C}-3 \mathrm{OH} .{ }^{18}$ Finally, the ability to discriminate among different hydroxyl groups on the A-ring has been demonstrated in the esterification of ecdysteroids catalysed by Candida antarctica lipase, which afforded the $2 \beta$-monoacyl derivatives in good yields. ${ }^{19}$

In this context, to further explore the enzymatic transformations of steroids, we endeavoured a systematic study on the selectivity of commercially available lipases towards a complete set of stereoisomeric 2,3- and 3,4-vicinal diols, to provide a new tool for the selective transformation of these molecules and of related natural compounds.

\section{Results and discussion}

Different synthetic strategies were used to afford the 
Table 1. Lipase-catalysed monoacylation of vicinal diols ${ }^{\mathrm{a}}$

\begin{tabular}{|c|c|c|c|c|c|c|c|c|c|}
\hline Substrate & $\begin{array}{l}\text { Novozym } \\
435\end{array}$ & $\begin{array}{l}\text { C. rugosa } \\
\text { lipase }\end{array}$ & $\begin{array}{l}\text { Lipase } \\
\text { AY }\end{array}$ & $\begin{array}{l}\text { Lipase } \\
\text { PS }\end{array}$ & $\begin{array}{l}\text { Lipase } \\
\text { AK }\end{array}$ & $\begin{array}{l}\text { C. viscosum } \\
\text { lipase }\end{array}$ & $\begin{array}{l}\text { Porcine pancreatic } \\
\text { lipase }\end{array}$ & $\begin{array}{l}\text { Lipozyme } \\
\text { IM } 20\end{array}$ & $\begin{array}{l}\text { Lipase } \\
\mathrm{CE}\end{array}$ \\
\hline 1 & - & ++ & + & + & + & + & - & - & - \\
\hline 2 & - & + & + & ++ & + & + & - & - & - \\
\hline 3 & ++ & - & - & - & - & - & - & - & - \\
\hline 4 & ++ & $+{ }^{b}$ & $+^{b}$ & ++ & - & - & - & - & - \\
\hline 5 & + & ++ & ++ & + & + & + & - & - & - \\
\hline 6 & + & + & + & + & + & ++ & - & - & - \\
\hline 7 & - & + & - & ++ & + & + & - & - & - \\
\hline 8 & - & - & - & - & - & - & & - & - \\
\hline
\end{tabular}

${ }^{a}$ Conversion and product(s) formation was evaluated by TLC.

${ }^{b}$ The formation of two products was observed.

requested stereoisomeric vicinal diols 1-8. Woodward's cisdihydroxylation method, which is known to be selective for the more hindered $\beta$-face of $5 \alpha$-steroids, ${ }^{20}$ was applied to $\Delta^{2}$ - or $\Delta^{3}$-unsaturated precursors affording the cis- $\beta$ diols 1 and 5 (Scheme 2). Complementarily, the cis- $\alpha$ diols 3 and 7 were accessed through osmium tetroxide-mediated dihydroxylation on the same olefins. ${ }^{21}$ Trans-diequatorial diols 2 and $\mathbf{6}$ were obtained by two different approaches. Starting from cholestan-3-one, $\alpha$-acetoxylation by lead tetracetate, ${ }^{22}$ followed by stereoselective reduction by $\mathrm{NaBH}_{4} / \mathrm{CeCl}_{3}$ and deacetylation rendered the diol 2. On the other hand, the $3 \beta, 4 \alpha$-diol 6 was directly accessed by hydroboration of the $\Delta^{4}$-3-one precursor. ${ }^{23}$ Finally, transdiaxial diols 4 and $\mathbf{8}$ were obtained by epoxide opening reactions.

As shown in the formula, the 2,3-diols were prepared by modifying the cholestane skeleton, whereas the difficulties found on separating the $5 \alpha$ - and $5 \beta$-epimers of $\Delta^{3}$-cholestane by sequential crystallizations led us to prepare the set of 3,4-diols in the androstane series. The cholestane derivative 9 was also synthesised to confirm that lipases selectivity towards the A-ring $\mathrm{OH}$ was not affected by different substituents on the D-ring.

The performances of a panel of 9 commercial lipases were evaluated for the esterification of the vicinal diols 1-9, using vinyl acetate as the acyl donor and toluene or acetone/THF as solvents for the cholestane or the androstane derivatives, respectively. TLC monitoring allowed the identification, for each substrate, of the lipase(s) able to promote the monoacylation of the substrates. As shown in Table 1, all the stereoisomeric vicinal diols were accepted as substrates by some of the enzymes tested with the exception of compound $\mathbf{8}$.

Lipases from different sources (Candida antarctica, column 2; Candida rugosa, columns 3 and 4; Pseudomonas strains, columns 5 and 6; Chromobacterium viscosum, column 7) were able to acylate the target compounds. Usually more than one enzyme was acting on the same substrate, with the notable exception of compound 3 ( $2 \alpha, 3 \alpha$-diol) acylated only by Novozym 435 (immobilized lipase B from Candida antarctica). Enzymatic acylations were highly regioselective, showing the formation of only one product by TLC, with the exception of Candida rugosa lipase (from Sigma or Amano) acting on compound 4. Noteworthy, lipase PS and Novozym 435 showed complementary regioselectivity towards compound 4 .

For each substrate the best performing lipase (evaluated by TLC) was chosen for scale-up reactions, allowing the isolation of the corresponding monoester in good yields (Scheme 1). Products identification was easily done by NMR analysis (downfield shift of the signals due to the proton geminal to the acylated $\mathrm{OH}$ ) and, when possible, by comparison with literature data.

The general preference of lipases for the $\mathrm{C}-3 \mathrm{OH}^{13,14}$ was observed with most of the substrates (Scheme 2). Specifically, the diequatorial vicinal diols $\mathbf{2}$ and $\mathbf{6}$ were converted into the corresponding $3 \beta$-acetate, showing a common preference of different lipases toward a $3 \beta$-equatorial $\mathrm{OH}$ in the presence of $2 \alpha$-equatorial $\mathrm{OH}$ (substrate 2 ) or of $4 \alpha$-equatorial $\mathrm{OH}$ (substrate 6).

Concerning the diaxial $2 \beta, 3 \alpha$ - and $3 \alpha, 4 \beta$-diols (substrates 4 and 8), different outcomes were noticed. The diaxial $2 \beta, 3 \alpha-$ diol was differently accepted by the lipases tested. Whereas Novozym 435 converted this diol exclusively into the $3 \alpha$-acetate 4a, lipase PS showed opposite selectivity rendering the $2 \beta$-acyl derivative $\mathbf{4 b}$ as the only product. Moreover, acylations catalysed by Candida rugosa lipases were not regioselective with this substrate. Conversely, the diaxial $3 \alpha, 4 \beta$ diol (8) was not accepted by any of the enzymes tested.

Finally, the equatorial/axial $2 \alpha, 3 \alpha$-diol (3), only accepted by Novozym 435 , was acylated at the axial $3 \alpha$-position, while, at variance, the $3 \alpha, 4 \alpha$-dihydroxy steroid (7) displaying axial/equatorial configuration, was acylated by different lipases at its equatorial $4 \alpha-\mathrm{OH}$.

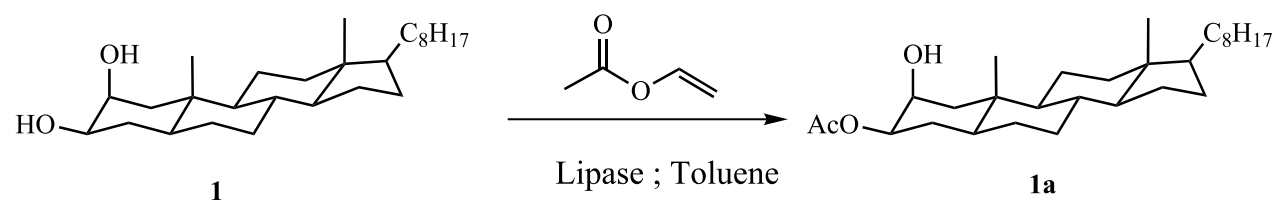

Scheme 1. 


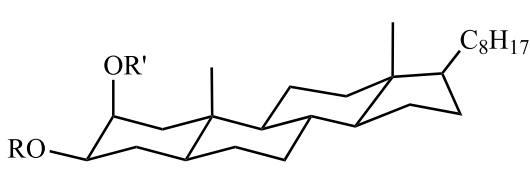

$1: \mathbf{R}, \mathbf{R}^{\prime}=\mathbf{H}$

1a $: \mathbf{R}=\mathbf{A c} ; \mathbf{R}^{\prime}=\mathbf{H}$

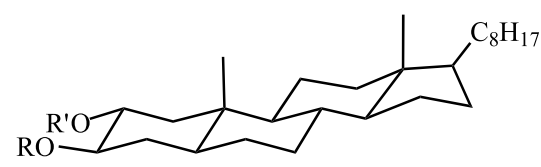

$2: \mathbf{R}, \mathbf{R}^{\prime}=\mathbf{H}$

$\mathbf{2 a}: \mathbf{R}=\mathbf{A c} ; \mathbf{R}^{\prime}=\mathbf{H}$
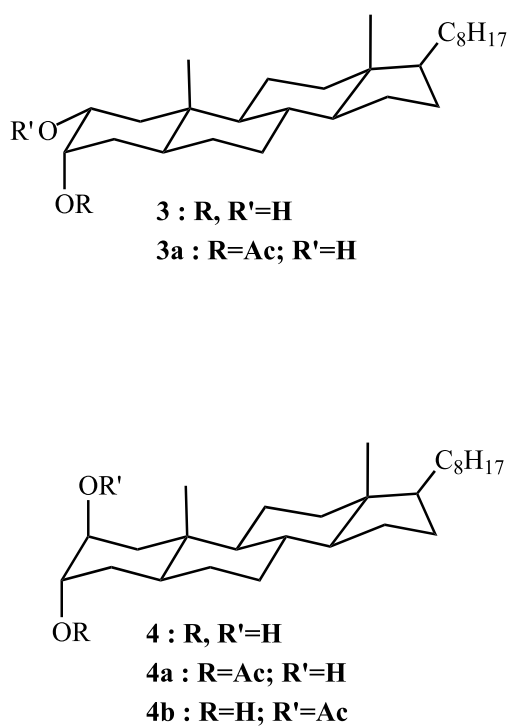

Scheme 2.

Moreover, in agreement with previous observations, the lipases tested did not catalyse any acylation of the $17 \beta-\mathrm{OH}$ (substrates 5-8), that was found unaffected in each of the isolated products.

The ability of Novozym 435 to accept axial $3 \alpha-\mathrm{OH}$ as a nucleophile has been reported previously. ${ }^{13 \mathrm{~d}}$ Herein, we noticed that this lipase catalyses the acylation of the $3 \alpha-\mathrm{OH}$ even when a second hydroxyl is located at C-2 (substrates $\mathbf{3}$ and 4), whereas the enzyme is inactive when the other $\mathrm{OH}$ is located at C-4 (substrates 7 and 8 ).

Concerning lipase PS, the ability of this enzyme to esterify 3-hydroxy steroids has been previously observed with $3 \beta$-hydroxy-5,6-epoxy derivatives. ${ }^{18}$ In the present work, lipase PS was found able to acylate most of the substrates (Table 1), catalysing their regioselective modification, not only at equatorial C-3 (product 2a), but also at equatorial C-4 (product 7a) and axial C-2 (product 4a). Noteworthy, among the panel of tested enzymes, lipase PS was the only one able to acylate hydroxy groups located at the latter positions.

Candida rugosa lipase accepted most of the substrates.
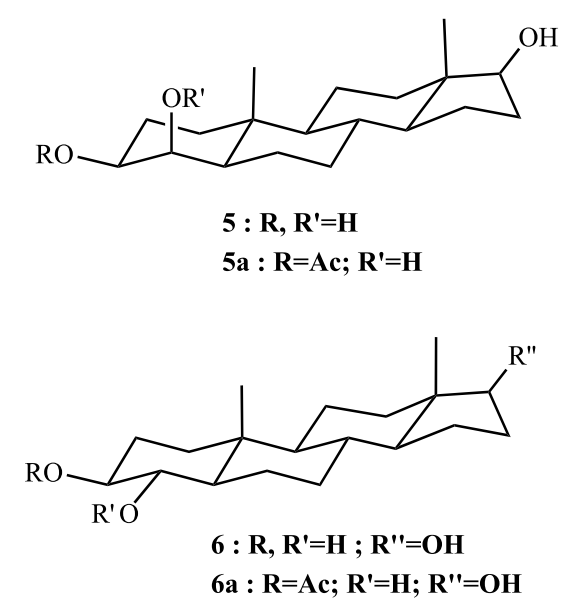

$9: \mathbf{R}, \mathbf{R}^{\prime}=\mathbf{H} ; \mathbf{R}^{\prime \prime}=\mathrm{C}_{8} \mathrm{H}_{17}$ 9a : $\mathbf{R}=A c ; R^{\prime}=H ; R^{\prime \prime}=C_{8} H_{17}$
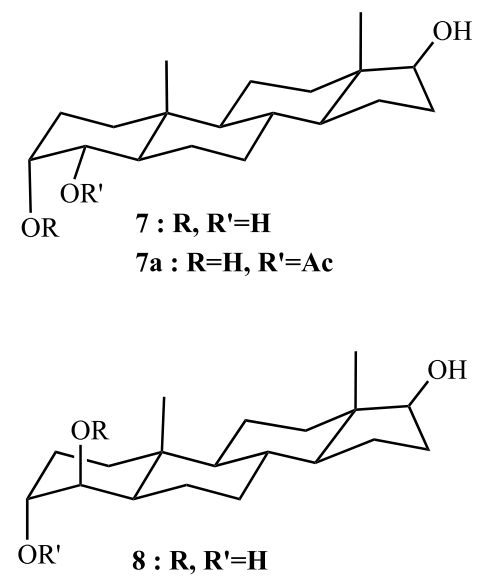

Specifically, this enzyme catalysed the acetylation of substrates 1, 2, 5 and $\mathbf{6}$ at their $3 \beta-\mathrm{OH}$, as was expectable from previous studies. ${ }^{13 b, c}$ However, the $3 \alpha, 4 \alpha$-diol 7 was also acylated by Candida rugosa lipase at the $\mathrm{C}-4 \mathrm{OH}$, and the $2 \beta, 3 \alpha$-diol 4 was acylated at both its hydroxy groups, showing that this enzyme has a quite variable affinity and selectivity pattern.

Chromobacterium viscosum lipase, which is known to have a strict selectivity for the $3 \beta$-hydroxyl of $5 \alpha$-steroids, ${ }^{14}$ showed the expected preference for diols carrying this $\mathrm{OH}$ (substrates 1, 2, 5 and 6). In addition, acylation of the substrate 7 was also noticed, but at the $4 \alpha-\mathrm{OH}$.

Finally, the substrate 9, a cholestane displaying $3 \beta, 4 \alpha$ diequatorial configuration, was converted into the $3 \beta$-monoacetate $9 \mathbf{a}$, a result which confirmed that the differences in the steroid side chain do not influence the selectivity of lipases.

\section{Conclusions}

The reported results clearly show that lipases are able to 
discriminate vicinal hydroxy groups located on the A-ring of steroids, being sensitive to the configuration of the different diols and affording the monoesters with high regioselectivity and good yields.

Considering the occurrence of steroidal vicinal diols in Nature, some of which being mono-acylated, ${ }^{3,6}$-glycosylated $^{4}$ or -sulphated, ${ }^{1,10}$ these findings can offer useful synthetic tools for the preparation of these compounds and of related derivatives.

\section{Experimental}

\subsection{General}

All commercially available chemicals were used as supplied by the manufacturers. Steroids, porcine pancreatic lipase (13.3 U/mg) and crude Candida rugosa lipase (665 U/mg) were from Sigma. Novozym 435 (8600 PLU/g) and Lipozyme IM 20 (24 BIU/g) were from Novozymes. Lipase PS (30.8 U/mg, from Pseudomonas cepacia) was purchased from Amano and adsorbed on celite as described elsewhere. ${ }^{16}$ Lipases AK (20 U/mg, from Pseudomonas fluorescens), CE (5.5 U/mg, from Humicola lanuginosa) and AY (30 U/mg, from Candida rugosa) were from Amano. Chromobacterium viscosum lipase (100 U/mg) was supplied by Finnsugar. ${ }^{1} \mathrm{H}$ and ${ }^{13} \mathrm{C}$ NMR spectra were recorded on a Bruker $\mathrm{AC}-300$ at $300 \mathrm{M} \mathrm{Hz}$ and at 75.47 $\mathrm{M} \mathrm{Hz}$, respectively, using $\mathrm{CDCl}_{3}$ and $\mathrm{CD}_{3} \mathrm{OD}$ as solvents. Chemical shifts are reported on the $\delta$ (ppm) scale and are relative to tetramethylsilane as internal standard. Infrared spectra were recorder on a Jasco FT/IR-420 spectrometer. Mass spectra were recorded on a GCT Micromass spectrometer. Melting points were measured in a Büchi B-540. Flash chromatography was performed using silica gel (230-400 Mesh) from Merck and petroleum ether/ ethyl acetate mixtures as eluents. TLC monitoring was done in petroleum ether/ethyl acetate as eluent and detected with the Komarowsky's reagent. ${ }^{24}$

\subsection{Chemical synthesis of the diols}

4.2.1. Cholestane-2 $\beta, 3 \beta$-diol (1). According to a known procedure, ${ }^{25}$ silica gel (70-230 Mesh, $100 \mathrm{~g}$ ) was added to a solution of $p$-toluenesulfonic acid $(3 \mathrm{~g})$ in acetone $(20 \mathrm{ml})$. The mixture was stirred, then evaporated under reduced pressure and left in a vacuum oven for 2 days. A mixture of cholestan-3 $\beta$-ol (1.17 g, $3 \mathrm{mmol}), p$-toluenesulfonic acid/ silica $(15 \mathrm{~g})$ and anhydrous toluene $(200 \mathrm{ml})$ was stirred under reflux, until the consumption of the starting material (24 h). After cooling, diethyl ether was added and the silica was removed by filtration. The organic solution was washed with water, saturated bicarbonate solution and brine. Upon evaporation, cholest-2-ene (1.0 g, 90\%) was recovered as a single product.

Selected data: ${ }^{1} \mathrm{H}$ NMR $\left(\mathrm{CDCl}_{3}\right) \delta: 0.66\left(3 \mathrm{H}, \mathrm{s}, \mathrm{CH}_{3}-18\right)$, $0.75\left(3 \mathrm{H}, \mathrm{s}, \mathrm{CH}_{3}-19\right), 0.86\left(6 \mathrm{H}\right.$, two d, $J=6.6 \mathrm{~Hz}, \mathrm{CH}_{3}-26$ and $\left.\mathrm{CH}_{3}-27\right), 0.90\left(3 \mathrm{H}, \mathrm{d}, J=6.5 \mathrm{~Hz}, \mathrm{CH}_{3}-21\right), 5.59(2 \mathrm{H}, \mathrm{m}$, $\mathrm{H}-2$ and H-3). ${ }^{13} \mathrm{C}$ NMR $\delta$ : $125.96,125.85,56.49,56.27$, 54.07, 42.47, 41.45, 40.03, 39.78, 39.51, 36.17, 35.79,
$35.61,34.69,31.82,30.31,28.77,28.22,28.00,24.20$, 23.82, 22.82, 22.56, 20.90, 18.68, 11.98, 11.67 .

To a solution of cholest-2-ene $(420 \mathrm{mg}, 1.15 \mathrm{mmol})$ in glacial acetic acid $(35 \mathrm{ml}), \mathrm{I}_{2}(600 \mathrm{mg})$ and $\mathrm{Cu}(\mathrm{OAc})_{2}$ $(500 \mathrm{mg})$ were added and the reaction mixture was refluxed under magnetic stirring. After $6 \mathrm{~h}$ the reaction was complete (TLC control). Then, toluene and $\mathrm{NaCl}$ were added and the insoluble salts were filtered off. Diethyl ether was added to the filtrate and the organic phase was washed with water and saturated sodium bicarbonate solution. Evaporation of the solvents under reduced pressure rendered the crude product, which was dissolved in ethanol/chloroform (4:1) $(20 \mathrm{ml})$, and treated with $\mathrm{NaOH} 16 \%$ aqueous solution $(1 \mathrm{ml})$ for $2 \mathrm{~h}$. Finally, upon addition of chloroform, the organic layers were washed with water, $\mathrm{HCl} 5 \%$, and brine and evaporated to dryness. The residue was purified by flash chromatography (petroleum ether/ethyl acetate $4: 1$ ), affording pure cholestane-2 $\beta, 3 \beta$-diol $(\mathbf{1}, 270 \mathrm{mg}, 58 \%)$, which was crystallized from $n$-hexane, mp $173-175^{\circ} \mathrm{C}$ (lit. $174-177^{21 \mathrm{a}}$ and $\left.175-176^{26} \mathrm{C}\right)$.

Selected data: ${ }^{1} \mathrm{H}$ NMR $\left(\mathrm{CDCl}_{3}\right) \delta: 0.65\left(3 \mathrm{H}, \mathrm{s}, \mathrm{CH}_{3}-18\right)$, $0.86\left(6 \mathrm{H}\right.$, two d, $J=6.6 \mathrm{~Hz}, \mathrm{CH}_{3}-26$ and $\left.\mathrm{CH}_{3}-27\right), 0.89(3 \mathrm{H}$, $\left.\mathrm{d}, J=6.5 \mathrm{~Hz}, \mathrm{CH}_{3}-21\right), 1.00\left(3 \mathrm{H}, \mathrm{s}, \mathrm{CH}_{3}-19\right), 3.63(1 \mathrm{H}, \mathrm{dt}$, $J=4.6,10.8 \mathrm{~Hz}, \mathrm{H}-3 \alpha), 4.02$ (1H, brq, H-2 $\alpha) .{ }^{13} \mathrm{C}$ NMR $\delta$ : $72.42,70.22,56.41,56.26,55.24,45.33,43.17,42.62$, $40.03,39.50,36.16,35.78,35.23,34.83,32.54,31.96$, $28.34,28.22,27.99,24.17,23.81,22.80,22.55,21.29$, 18.64, 14.56, 12.09. FTIR (ATR): $\nu_{\max } 1049.1,2850.3-$ $2931.3,3311.2 \mathrm{~cm}^{-1}$.

4.2.2. Cholestane-2 $\alpha, 3 \beta$-diol (2). Glacial acetic acid $(60 \mathrm{ml})$ was refluxed with acetic anhydride $(5 \mathrm{ml})$ for $10 \mathrm{~min}$, then cholestan-3-one (769 $\mathrm{mg}, 2 \mathrm{mmol})$ was added and, finally, lead tetracetate $(1.5 \mathrm{~g}, 3.4 \mathrm{mmol})$ was slowly added. The reaction was heated under reflux, with magnetic stirring until the consumption of the starting material $(24 \mathrm{~h})$. After cooling, diethyl ether was added and the organic solution was washed with $\mathrm{HCl} 5 \%$, saturated bicarbonate solution and brine. The crude product was purified by flash chromatography (petroleum ether/ethyl acetate 5:1) affording pure 3 -oxocholestan-2 $\alpha$-yl acetate (710 mg, 80\%), as a white amorphous powder, mp $120-122^{\circ} \mathrm{C}$ (lit. ${ }^{27} 124.7-$ $125.2^{\circ} \mathrm{C}$ ).

Selected data: ${ }^{1} \mathrm{H}$ NMR $\left(\mathrm{CDCl}_{3}\right) \delta: 0.67\left(3 \mathrm{H}, \mathrm{s}, \mathrm{CH}_{3}-18\right)$, $0.850 .91\left(9 \mathrm{H}, \mathrm{CH}_{3}-21, \mathrm{CH}_{3}-26\right.$ and $\left.\mathrm{CH}_{3}-27\right), 1.12(3 \mathrm{H}, \mathrm{s}$, $\left.\mathrm{CH}_{3}-19\right), 2.15\left(3 \mathrm{H}, \mathrm{s}, \mathrm{CH}_{3} \mathrm{CO}\right), 5.29(1 \mathrm{H}, \mathrm{dd}, J=6.6$, $12.9 \mathrm{~Hz}, \mathrm{H}-2 \beta) .{ }^{13} \mathrm{C}$ NMR $\delta: 204.3,170.15,74.46,56.16$, 56.06, 53.78, 47.84, 44.82, 43.57, 42.56, 39.71, 39.47, $37.18,36.10,35.74,34.67,31.56,28.38,28.20,27.99$, $24.16,23.78,22.80,22.54,21.60,20.79,18.63,12.75$, 12.04. FTIR (ATR): $\nu_{\max } 1222.7,1727.9,1750.1 \mathrm{~cm}^{-1}$.

To a solution of 3-oxocholestan- $2 \alpha$-yl acetate $(700 \mathrm{mg}$, $1.6 \mathrm{mmol}$ ) in $\mathrm{THF} / \mathrm{methanol} 2: 1, \mathrm{CeCl}_{3} \cdot 7 \mathrm{H}_{2} \mathrm{O}(745 \mathrm{mg}$, $2 \mathrm{mmol}$ ) was added and the mixture was stirred for $10 \mathrm{~min}$ at room temperature before $\mathrm{NaBH}_{4}(120 \mathrm{mg}, 3.2 \mathrm{mmol}$, 8 equiv) was slowly added. After $30 \mathrm{~min}$, the reaction was complete (TLC monitoring) and $\mathrm{HCl} 5 \%$ was added dropwise. The mixture was poured into water and extracted with diethyl ether. The organic solution was washed with 
$\mathrm{HCl} 5 \%$, saturated bicarbonate solution and brine, and evaporated to dryness, yielding $3 \beta$-hydroxycholestan- $2 \alpha$-yl acetate $(641 \mathrm{mg}, 91 \%)$, as a white powder, $\mathrm{mp} 73-75^{\circ} \mathrm{C}$.

Selected data: ${ }^{1} \mathrm{H}$ NMR $\left(\mathrm{CDCl}_{3}\right) \delta: 0.64\left(3 \mathrm{H}, \mathrm{s}, \mathrm{CH}_{3}-18\right)$, 0.84-0.90 (12H, $\left.\mathrm{CH}_{3}-19, \mathrm{CH}_{3}-21, \mathrm{CH}_{3}-26, \mathrm{CH}_{3}-27\right), 2.08$ (3H, s, $\left.\mathrm{CH}_{3} \mathrm{CO}\right), 3.59$ (1H, ddd, $\left.J=5.4,9.5,11.1 \mathrm{~Hz}, \mathrm{H}-3 \alpha\right)$, $4.82(1 \mathrm{H}$, ddd, $J=4.8,9.4,11.6 \mathrm{~Hz}, \mathrm{H}-2 \beta) .{ }^{13} \mathrm{C}$ NMR $\delta$ : $171.59,76.49,73.53,56.28,56.17,54.17,44.43,42.52$, $42.12,39.81,39.47,37.27,36.11,35.89,35.73,34.70$, $31.79,28.19,27.97,27.77,24.15,23.77,22.79,22.53$, $21.38,18.63,13.09,12.02$.

$3 \beta$-Hydroxycholestan- $2 \alpha$-yl acetate $(500 \mathrm{mg}, 1.12 \mathrm{mmol}$ ) was treated with $\mathrm{NaOH}$ as described in Section 4.2.1. The crude product was purified by flash chromatography (petroleum ether/ethyl acetate $4: 1$ ), rendering cholestane$2 \alpha, 3 \beta$-diol $(2,370 \mathrm{mg}, 82 \%)$, which was crystallized from methanol, mp 196.0-197.5 ${ }^{\circ} \mathrm{C}$ (lit. ${ }^{22 \mathrm{~b}} 204^{\circ} \mathrm{C}$ ).

Selected data: ${ }^{1} \mathrm{H}$ NMR $\left(\mathrm{CDCl}_{3}\right) \delta: 0.64\left(3 \mathrm{H}, \mathrm{s}, \mathrm{CH}_{3}-18\right)$, 0.84-0.91 (12H, $\left.\mathrm{CH}_{3}-19, \mathrm{CH}_{3}-21, \mathrm{CH}_{3}-26, \mathrm{CH}_{3}-27\right), 3.40$ $(1 \mathrm{H}, \mathrm{ddd}, J=5.1,8.9,10.9 \mathrm{~Hz}, \mathrm{H}-3 \alpha), 3.59$ (1H, ddd, $J=$ 4.7, 9.0, $11.5 \mathrm{~Hz}, \mathrm{H}-2 \beta) .{ }^{13} \mathrm{C}$ NMR $\delta: 73.11,72.3,56.30$, $56.20,54.26,45.03,44.83,39.89,39.48,38.14,37.46$, $36.13,35.77,35.57,34.73,31.88,28.23,28.00,27.91$, $24.17,23.80,22.81,22.55,21.36,18.64,13.50,12.04$. FTIR (ATR): $\nu_{\max } 1051.0,2850.1-2930.3,3312.9 \mathrm{~cm}^{-1}$.

4.2.3. Cholestane-2 $\boldsymbol{\alpha}, 3 \boldsymbol{\alpha}$-diol (3). A solution of $\mathrm{K}_{3} \mathrm{Fe}(\mathrm{CN})_{6}$ $(1 \mathrm{~g}), \mathrm{Et}_{3} \mathrm{~N}(7 \mu \mathrm{l}), \mathrm{K}_{2} \mathrm{CO}_{3}(420 \mathrm{mg})$ and methanesulphonamide $(96 \mathrm{mg})$ in $20 \mathrm{ml}$ of $t-\mathrm{BuOH} / \mathrm{H}_{2} \mathrm{O}(3: 2)$ was prepared. Cholest-2-ene (370 mg, $1 \mathrm{mmol}$ ), (Section 4.2.1) was dissolved in $30 \mathrm{ml} \mathrm{THF} / t-\mathrm{BuOH} / \mathrm{H}_{2} \mathrm{O}$ (10:3:2) and added to the previous solution. Then, $30 \mu \mathrm{l}$ of $\mathrm{OsO}_{4}$ solution $\left(0.1 \mathrm{mg} / \mu \mathrm{l}\right.$ in $\left.\mathrm{CH}_{3} \mathrm{CN}\right)$ was added and the reaction was stirred at room temperature until the total consumption of the starting material $(48 \mathrm{~h})$. Sodium sulphite $5 \%$ was added and the mixture was stirred for $5 \mathrm{~h}$. Upon addition of diethyl ether, the organic layer was washed with $\mathrm{HCl} 5 \%$, saturated bicarbonate solution and brine, and then, evaporated. The residue was purified by flash chromatography (petroleum ether/ethyl acetate $4: 1$ ), rendering cholestane- $2 \alpha, 3 \alpha$-diol (3, $242 \mathrm{mg})$, which was crystallized from $n$-hexane, $\mathrm{mp}$ 217-218 ${ }^{\circ} \mathrm{C}$ (lit. $^{22 \mathrm{~b}} 216-219^{\circ} \mathrm{C}$ ).

Selected data: ${ }^{1} \mathrm{H}$ NMR $\left(\mathrm{CDCl}_{3}\right) \delta: 0.65\left(3 \mathrm{H}, \mathrm{s}, \mathrm{CH}_{3}-18\right)$, 0.80 (3H, s, $\left.\mathrm{CH}_{3}-19\right), 0.86\left(6 \mathrm{H}\right.$, two d, $J=6.6 \mathrm{~Hz}, \mathrm{CH}_{3}-26$ and $\left.\mathrm{CH}_{3}-27\right), 0.90\left(3 \mathrm{H}, \mathrm{d}, J=6.6 \mathrm{~Hz}, \mathrm{CH}_{3}-21\right), 3.77(1 \mathrm{H}$, br $\mathrm{d}, J=11.0 \mathrm{~Hz}, 2 \beta-\mathrm{H}), 3.96(1 \mathrm{H}$, br s, $3 \beta-\mathrm{H}) .{ }^{13} \mathrm{C}$ NMR $\delta$ : $69.27,69.12,56.35,56.16,54.16,42.55,40.93,39.90$, $39.49,38.14,36.90,36.13,35.78,34.76,34.22,31.82$, $28.22,28.00,27.65,24.17,23.80,22.81,22.55,20.90$, 18.65, 12.40, 12.06. FTIR (ATR): $\nu_{\max } 1048.7,2852.2-$ $2930.0,3315.0 \mathrm{~cm}^{-1}$.

4.2.4. Cholestane-2 $\beta, 3 \alpha$-diol (4). A mixture of cholest-2ene $(400 \mathrm{mg}, 1.1 \mathrm{mmol}), \mathrm{CHCl}_{3}(15 \mathrm{ml})$ and 3-chloroperoxybenzoic acid (400 $\mathrm{mg}, 2.3 \mathrm{mmol}$ ) was stirred at room temperature. After the disappearance of the starting material $(24 \mathrm{~h})$, the reaction mixture was poured into water and extracted with $\mathrm{CH}_{2} \mathrm{Cl}_{2}$. The organic phase was washed with sodium sulphite 5\%, water and brine, dried with $\mathrm{MgSO}_{4}$ and evaporated at reduced pressure, affording $2 \alpha, 3 \alpha$-epoxycholestane (395 mg, 93\%).

Selected data: ${ }^{1} \mathrm{H}$ NMR $\left(\mathrm{CDCl}_{3}\right) \delta: 0.64\left(3 \mathrm{H}, \mathrm{s}, \mathrm{CH}_{3}-18\right)$, $0.75\left(3 \mathrm{H}, \mathrm{s}, \mathrm{CH}_{3}-19\right), 0.86\left(6 \mathrm{H}\right.$, two d, $J=6.6 \mathrm{~Hz}, \mathrm{CH}_{3}-26$ and $\left.\mathrm{CH}_{3}-27\right), 0.90\left(3 \mathrm{H}, \mathrm{d}, J=6.5 \mathrm{~Hz}, \mathrm{CH}_{3}-21\right), 3.14(2 \mathrm{H}, \mathrm{m}$, $\mathrm{H}-2 \beta$ and $\mathrm{H}-3 \beta)$.

According to a known procedure, ${ }^{28}$ to a solution of $2 \alpha, 3 \alpha$ epoxycholestane $(374 \mathrm{mg}, 0.9 \mathrm{mmol})$ in acetone $(30 \mathrm{ml})$, periodic acid $(350 \mathrm{mg})$ in acetone/water $(1: 1.5 \mathrm{ml})$ was added and the mixture was heated to reflux for $5 \mathrm{~min}$, then concentrated until 1/3 of the initial volume and kept at room temperature for $30 \mathrm{~min}$. This mixture was refluxed again while water $(2 \mathrm{ml})$ was added dropwise for $30 \mathrm{~min}$. Finally, the mixture was cooled, concentrated under vacuum and purified by flash chromatography (petroleum ether/ethyl acetate 4:1), yielding cholestane-2 $\beta, 3 \alpha$-diol (4, $309 \mathrm{mg}$, $85 \%)$, which was crystallized from methanol, mp 183-

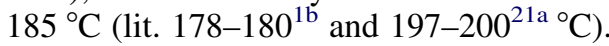

Selected data: ${ }^{1} \mathrm{H}$ NMR $\left(\mathrm{CDCl}_{3}\right) \delta: 0.65\left(3 \mathrm{H}, \mathrm{s}, \mathrm{CH}_{3}-18\right)$, $0.86\left(6 \mathrm{H}\right.$, two d, $J=6.6 \mathrm{~Hz}, \mathrm{CH}_{3}-26$ and $\left.\mathrm{CH}_{3}-27\right), 0.90(3 \mathrm{H}$, $\left.\mathrm{d}, J=6.5 \mathrm{~Hz}, \mathrm{CH}_{3}-21\right), 0.99$ (3H, s, $\left.\mathrm{CH}_{3}-19\right), 3.87$ (2H, m, $\mathrm{H}-2 \alpha$ and $\mathrm{H}-3 \beta) .{ }^{13} \mathrm{C}$ NMR $\delta: 71.82,70.61,56.41,56.19$, $55.10,42.60,40.54,40.01,39.49,38.93,36.14,35.78$, $35.73,34.88,31.90,31.71,28.20,28.01,24.13,23.80$, $22.82,22.55,20.86,18.64,14.59,12.10$. FTIR (ATR): $\nu_{\max }$ $1047.9,2843.2-2930.9,3310.1 \mathrm{~cm}^{-1}$.

4.2.5. Androstane-3 $\beta, 4 \beta, 17 \beta$-triol (5). A mixture of testosterone acetate $(661 \mathrm{mg}, 2 \mathrm{mmol})$, glacial acetic acid $(30 \mathrm{ml})$ and zinc dust $(4 \mathrm{~g})$ was stirred at room temperature. After disappearance of the starting material $(5 \mathrm{~h})$, diethyl ether was added and the suspension was filtered through a celite pad. The filtrate was evaporated under reduced pressure, then dissolved in diethyl ether and washed with water, saturated sodium bicarbonate solution and brine. After drying with $\mathrm{MgSO}_{4}$, the organic phase was evaporated, affording an epimeric mixture of $5 \alpha$ - and $5 \beta$-androst3-en-17 $\beta$-yl acetate (595 mg, 94\%).

Selected data: ${ }^{1} \mathrm{H}$ NMR $\left(\mathrm{CDCl}_{3}\right) \delta: 0.78\left(3 \mathrm{H}, \mathrm{s}, 18-\mathrm{CH}_{3}\right)$, 0.80 and $0.96\left(3 \mathrm{H}\right.$, two s, 19- $\left.\mathrm{CH}_{3}\right), 2.03\left(3 \mathrm{H}, \mathrm{s}, \mathrm{CH}_{3} \mathrm{CO}\right)$, $4.56(1 \mathrm{H}, \mathrm{m}, \mathrm{H}-17 \alpha), 5.29(1 \mathrm{H}, \mathrm{dq}, \mathrm{H}-4), 5.54$ and $5.66(1 \mathrm{H}$, two $\mathrm{m}, \mathrm{H}-3)$. The $5 \alpha$ - and $5 \beta$ - epimeric ratio, evaluated by the integration of the H-3 multiplets, ${ }^{29}$ was 0.8:1. Epimerically pure $5 \alpha$-androst-3-en-17 $\beta$-yl acetate was obtained after 3 sequential crystallizations in $n$-hexane.

$5 \alpha$-Androst-3-en-17 $\beta$-yl acetate $(200 \mathrm{mg}, 0.63 \mathrm{mmol})$ reacted with $\mathrm{I}_{2} / \mathrm{Cu}(\mathrm{OAc})_{2}$, the product obtained was treated with $\mathrm{NaOH}$ (Section 4.2.1) and purified by flash chromatography (petroleum ether/ethyl acetate 1:2), rendering androstane-3 $\beta, 4 \beta, 17 \beta$-triol $(\mathbf{5}, 95 \mathrm{mg})$, as a white amorphous powder, mp $257-260{ }^{\circ} \mathrm{C}$ (lit. ${ }^{30} 263-265^{\circ} \mathrm{C}$ ).

Selected data: ${ }^{1} \mathrm{H}$ NMR $\left(\mathrm{CDCl}_{3} / \mathrm{CD}_{3} \mathrm{OD}\right) \delta: 0.72(3 \mathrm{H}, \mathrm{s}$, $\left.\mathrm{CH}_{3}-18\right), 1.04$ (3H, s, $\left.\mathrm{CH}_{3}-19\right), 3.50$ (1H, m, H-3 $\left.\alpha\right), 3.57$ $(1 \mathrm{H}, \mathrm{t}, J=8.6 \mathrm{~Hz}, \mathrm{H}-17 \alpha), 3.68(1 \mathrm{H}$, br t,$J=2.30 \mathrm{~Hz}$, $\mathrm{H}-4 \alpha) .{ }^{13} \mathrm{C}$ NMR $\delta: 81.89,75.12,72.67,56.03,51.64,43.42$, 37.66 , 37.17, 36.12, 36.05, 32.54, 30.09, 26.34, 25.80, 
23.79, 20.69, 14.98, 11.42. FTIR (ATR): $\nu_{\max }$ 1064.6, $2845.5-2934.2,3308.3 \mathrm{~cm}^{-1}$.

4.2.6. Androstane-3 $\beta, 4 \alpha, 17 \beta$-triol (6). Testosterone $(288.4 \mathrm{mg}, 1 \mathrm{mmol})$ was dissolved in THF $(10 \mathrm{ml})$ and cooled to $0{ }^{\circ} \mathrm{C}$. Then, $\mathrm{BH}_{3}$ in THF $(1.0 \mathrm{M}, 5 \mathrm{ml})$ was added slowly. The mixture was stirred for $3 \mathrm{~h}$, then warmed to room temperature over $2.5 \mathrm{~h}$ and cautiously quenched with a $10 \mathrm{~N} \mathrm{NaOH}$ aqueous solution $(2 \mathrm{ml})$, followed by slow addition of a $30 \% \mathrm{H}_{2} \mathrm{O}_{2}$ aqueous solution $(2 \mathrm{ml})$. This mixture was stirred overnight, then poured into water and extracted with diethyl ether. The organic layers were washed with $\mathrm{HCl} 5 \%$, saturated bicarbonate solution and brine. After drying with $\mathrm{MgSO}_{4}$, the solvent was evaporated at reduced pressure and the residue purified by flash chromatography (petroleum ether/ethyl acetate 1:2), rendering androstane-3 $\beta, 4 \alpha, 17 \beta$-triol $(6,246 \mathrm{mg}, 80 \%)$, which was crystallized from methanol, $\mathrm{mp} 253.3-255.8^{\circ} \mathrm{C}$ (lit. $248-250^{23 \mathrm{a}}$ and $258-259^{30}{ }^{\circ} \mathrm{C}$ ).

Selected data: ${ }^{1} \mathrm{H}$ NMR $\left(\mathrm{CDCl}_{3} / \mathrm{CD}_{3} \mathrm{OD}\right) \delta: 0.72(3 \mathrm{H}, \mathrm{s}$, $\left.\mathrm{CH}_{3}-18\right), 0.85\left(3 \mathrm{H}, \mathrm{s}, \mathrm{CH}_{3}-19\right), 3.20(1 \mathrm{H}, \mathrm{t}, J=8.7 \mathrm{~Hz}$, $\mathrm{H}-4 \beta$ ), 3.29 (1H, m, H-3 $\alpha$ ), 3.59 (1H, t, $J=8.5 \mathrm{~Hz}, \mathrm{H}-17 \alpha$ ). ${ }^{13} \mathrm{C}$ NMR $\delta: 81.87,76.52,75.53,55.24,51.53,51.48,43.38$, $37.75,37.23,36.85,35.68,31.76,30.13,28.78,23.77$, $23.10,21.10,13.89,11.47$. FTIR (ATR): $\nu_{\max } 1066.0$, $2847.5-2932.0,3309.1 \mathrm{~cm}^{-1}$.

4.2.7. Androstane-3 $\alpha, 4 \alpha, 17 \beta$-triol (7). $5 \alpha$-Androst-3-en$17 \beta$-yl acetate $(200 \mathrm{mg}, 0.63 \mathrm{mmol}$ ) (Section 4.2 .5$)$ was oxidized by $\mathrm{OsO}_{4}$ (Section 4.2.3). The product was treated with $\mathrm{NaOH}$ (Section 4.2.1) and purified by flash chromatography (petroleum ether/ethyl acetate 1:2), affording androstane- $3 \alpha, 4 \alpha, 17 \beta$-triol $(7,110.6 \mathrm{mg}, 57 \%)$.

Selected data: ${ }^{1} \mathrm{H}$ NMR $\left(\mathrm{CDCl}_{3} / \mathrm{CD}_{3} \mathrm{OD}\right) \delta: 0.72(3 \mathrm{H}, \mathrm{s}$, $\left.\mathrm{CH}_{3}-18\right), 0.85\left(3 \mathrm{H}, \mathrm{s}, \mathrm{CH}_{3}-19\right), 3.45(1 \mathrm{H}, \mathrm{d}, J=10.2 \mathrm{~Hz}$, $\mathrm{H}-4 \beta), 3.6(1 \mathrm{H}, \mathrm{t}, J=8.5 \mathrm{~Hz}, \mathrm{H}-17 \alpha), 3.97(1 \mathrm{H}, \mathrm{s}, \mathrm{H}-3 \beta)$. ${ }^{13} \mathrm{C}$ NMR $\delta: 82.40,73.56,70.14,54.19,50.76,42.52,37.50$, $37.11,36.89,34.90,31.76,31.10,23.47,22.58,21.20$, $20.30,12.70,11.49$. FTIR (ATR): $\nu_{\max } 1065.0,2846.1-$ $2933.3,3307.8 \mathrm{~cm}^{-1}$.

4.2.8. Androstane-3 $\alpha, 4 \beta, 17 \beta$-triol (8). $5 \alpha$-Androst-3-en$17 \beta$-yl acetate $(290 \mathrm{mg}, 0.92 \mathrm{mmol})$ obtained as described above (2.5) reacted with 3-chloroperoxybenzoic (Section 4.2.4). The product obtained was treated with periodic acid (Section 4.2.4), deacetylated with $\mathrm{NaOH}$ (Section 4.2.1) and purified by flash chromatography (petroleum ether/ ethyl acetate 1:2), affording androstane- $3 \alpha, 4 \beta, 17 \beta$-triol $(8,142 \mathrm{mg}$ ), which was crystallized from methanol, $\mathrm{mp}$ $263-264.3^{\circ} \mathrm{C}$.

Selected data: ${ }^{1} \mathrm{H}$ NMR $\left(\mathrm{CDCl}_{3} / \mathrm{CD}_{3} \mathrm{OD}\right) \delta: 0.71(3 \mathrm{H}, \mathrm{s}$, $\left.\mathrm{CH}_{3}-18\right), 1.03$ (3H, s, $\left.\mathrm{CH}_{3}-19\right), 3.49(1 \mathrm{H}$, br s, $\mathrm{H}-4 \alpha), 3.55$ $(1 \mathrm{H}, \mathrm{t}, J=8.6 \mathrm{~Hz}, \mathrm{H}-17 \alpha), 3.75(1 \mathrm{H}, \mathrm{brq}, J=2.6 \mathrm{~Hz}, \mathrm{H}-3 \beta)$. ${ }^{13}$ C NMR $\delta: 82.54,76.56,71.24,56.94,52.51,45.24,44.08$, $37.99,37.09,36.96,33.32,33.21,30.61,26.60,25.11$, $24.31,20.97,14.85,11.67$. FTIR (ATR): $\nu_{\max } 1064.9$, $2849.8-2935.1,3309.5 \mathrm{~cm}^{-1}$. FD-MS $\mathrm{m} / \mathrm{z}=308.2386$ $\left(100 \%, \mathrm{M}^{+}\right), 309.2424\left(27 \%, \mathrm{M}^{+}+1\right), 290.2237(17 \%$, $\left.\mathrm{M}^{+}-\mathrm{H}_{2} \mathrm{O}\right)$.

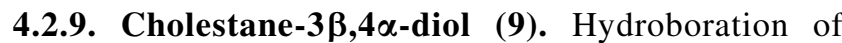
cholest-4-en-3-one (384 mg, $1 \mathrm{mmol}$ ) under the conditions described in Section 4.2.8 rendered cholestane-3 $\beta, 4 \alpha$-diol $(\mathbf{9}, 352 \mathrm{mg}, 87 \%)$, which was crystallized from $n$-hexane, mp $235-237^{\circ} \mathrm{C}$ (lit. ${ }^{31} 237^{\circ} \mathrm{C}$ ).

Selected data: ${ }^{1} \mathrm{H}$ NMR $\left(\mathrm{CDCl}_{3}\right) \delta: 0.62\left(3 \mathrm{H}, \mathrm{s}, \mathrm{CH}_{3}-18\right)$, 0.79-0.87 (12H, $\left.\mathrm{CH}_{3}-19, \mathrm{CH}_{3}-21, \mathrm{CH}_{3}-26, \mathrm{CH}_{3}-27\right), 3.18$ $(1 \mathrm{H}, \mathrm{t}, J=10.2 \mathrm{~Hz}, \mathrm{H}-4 \beta), 3.29(1 \mathrm{H}, \mathrm{m}, \mathrm{H}-3 \alpha) .{ }^{13} \mathrm{C}$ NMR $\delta$ : $76.24,75.25,56.54,56.37,54.6,50.86,42.63,40.08,39.62$, $37.28,36.36,36.27,35.92,35.16,31.74,28.37,28.26$, $28.11,24.28,23.93,22.83,22.78,22.58,21.08,18.70$, 13.58, 12.11. FTIR (ATR): $\nu_{\max } 1047.1,2851.2-2930.2$, $3315.0 \mathrm{~cm}^{-1}$.

\subsection{Enzymatic acylation of 2,3- and 3,4-vicinal diols}

In a typical screening assay, a solution of the substrate $(2 \mathrm{mg}$ ), in $0.9 \mathrm{ml}$ of solvent (toluene for the cholestane diols or acetone/THF for the androstane diols) and vinyl acetate $(0.1 \mathrm{ml})$ was prepared. This solution was added to the enzyme (30 mg of crude enzymes, $10 \mathrm{mg}$ of Lipozyme IM 20 or $5 \mathrm{mg}$ of Novozym 435) in $3 \mathrm{ml}$ vials, which were stopped with a cap and shaken at $250 \mathrm{rpm}$ at $45^{\circ} \mathrm{C}$. The reactions were monitored by TLC (see Table 1 ).

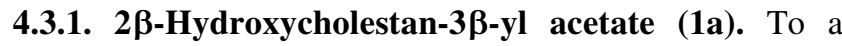
solution of cholestane- $2 \beta, 3 \beta$-diol (1,25 mg, $0.062 \mathrm{mmol})$ in toluene $(8 \mathrm{ml})$ and vinyl acetate $(2 \mathrm{ml})$, Candida rugosa lipase $(100 \mathrm{mg})$ was added and the reaction was shaken at $250 \mathrm{rpm}$, at $45^{\circ} \mathrm{C}$. After $24 \mathrm{~h}$ the reaction was complete. The enzyme was filtered off and the solvent was evaporated, the residue was purified by flash chromatography (petroleum ether/ethyl acetate 5:1) yielding $2 \beta$-hydroxycholestan$3 \beta$-yl acetate (1a, $22 \mathrm{mg}, 80 \%$ ), which was crystallized from methanol, mp $147-148^{\circ} \mathrm{C}$ (lit. ${ }^{26} 154^{\circ} \mathrm{C}$ ).

Selected data: ${ }^{1} \mathrm{H}$ NMR $\left(\mathrm{CDCl}_{3}\right) \delta: 0.65\left(3 \mathrm{H}, \mathrm{s}, \mathrm{CH}_{3}-18\right)$, $0.86\left(6 \mathrm{H}\right.$, two d, $J=6.5 \mathrm{~Hz}, \mathrm{CH}_{3}-26$ and $\left.\mathrm{CH}_{3}-27\right), 0.89(3 \mathrm{H}$, d, $\left.J=6.5 \mathrm{~Hz}, \mathrm{CH}_{3}-21\right), 1.03\left(3 \mathrm{H}, \mathrm{s}, \mathrm{CH}_{3}-19\right), 2.08(3 \mathrm{H}, \mathrm{s}$, $\left.\mathrm{CH}_{3} \mathrm{CO}\right), 4.09(1 \mathrm{H}, \mathrm{br} \mathrm{q}, J=2.6 \mathrm{~Hz}, \mathrm{H}-2 \alpha), 4.78(1 \mathrm{H}, \mathrm{ddd}$, $J=3.34,4.71,11.75 \mathrm{~Hz}, \mathrm{H}-3 \alpha) .{ }^{13} \mathrm{C}$ NMR $\delta: 170.13,75.58$, $68.72,56.30,56.19,55.15,45.40,42.90,42.59,39.95$, $39.47,36.12,35.76,35.30,34.77,31.86,28.58,28.20$, $28.13,27.98,24.13,23.79,22.80,22.54,21.34,21.22$, 18.62, 14.51, 12.07. FTIR (ATR): $\nu_{\max } 1025.1,1259.3$, $1721.8,2858.0-2950.2,3510.8 \mathrm{~cm}^{-1}$. FD-MS $\mathrm{m} / \mathrm{z}=$ $386.3462\left(100 \%, \mathrm{M}^{+}-\mathrm{CH}_{3} \mathrm{COOH}\right), 447.3828(83 \%$, $\left.\mathrm{M}^{+}+1\right), 404.3776\left(67 \%, \mathrm{M}^{+}+1-\mathrm{CH}_{3} \mathrm{CO}\right), 448.3870$ $\left(25 \%, \mathrm{M}^{+}+2\right), 61.0324\left(8 \%, \mathrm{CH}_{3} \mathrm{COOH}+1\right)$.

4.3.2. $2 \alpha$-Hydroxycholestane-3 $\beta$-yl acetate (2a). To a solution of cholestane- $2 \alpha, 3 \beta$-diol (2,50 mg, $0.124 \mathrm{mmol})$ in toluene $(8 \mathrm{ml})$, vinyl acetate $(1 \mathrm{ml})$ and lipase PS $(100 \mathrm{mg})$ were added and the reaction mixture was shaken for $24 \mathrm{~h}$, under the conditions described above. After usual work-up and purification by flash chromatography, $2 \alpha$ hydroxycholestane-3 3 -yl acetate was recovered (2a, $48 \mathrm{mg}$, $87 \%$ ) as a white powder, mp $157-159^{\circ} \mathrm{C}$. The TLC $R_{\mathrm{f}}$ of $\mathbf{2 a}$ and of $3 \beta$-hydroxycholestan- $2 \alpha$-yl acetate (synthesised in Section 4.2.2) using petroleum ether/ethyl acetate (2:1) as eluent were 0.47 , and 0.39 , respectively. 
Selected data: ${ }^{1} \mathrm{H}$ NMR $\left(\mathrm{CDCl}_{3}\right) \delta: 0.65\left(3 \mathrm{H}, \mathrm{s}, \mathrm{CH}_{3}-18\right)$, 0.84-0.90 (12H, $\left.\mathrm{CH}_{3}-19, \mathrm{CH}_{3}-21, \mathrm{CH}_{3}-26, \mathrm{CH}_{3}-27\right), 2.08$ (3H, s, $\left.\mathrm{CH}_{3} \mathrm{CO}\right), 3.77$ (1H, ddd, $\left.J=4.8,9.4,11.5 \mathrm{~Hz}, \mathrm{H}-2 \beta\right)$, $4.59(1 \mathrm{H}$, ddd, $J=5.4,9.5,10.9 \mathrm{~Hz}, \mathrm{H}-3 \alpha) .{ }^{13} \mathrm{C}$ NMR $\delta$ : $171.37,78.99,69.85,56.13,56.09,54.03,45.28,44.34$, $42.46,39.75,39.39,36.81,36.03,35.68,34.62,32.53$, $31.69,30.82,28.13,27.90,27.63,24.08,23.70,22.70$, $22.44,21.25,18.54,13.17,11.94$. FTIR (ATR): $\nu_{\max } 1025.9$, $1259.8,1718.8,2857.0-2951.3,3512.1 \mathrm{~cm}^{-1}$. FI-MS $\mathrm{m} / \mathrm{z}=$ $386.3553\left(100 \%, \mathrm{M}^{+}-\mathrm{CH}_{3} \mathrm{COOH}\right), 446.3842\left(54 \%, \mathrm{M}^{+}\right)$, $387.3591\left(35 \%, \mathrm{M}^{+}+1-\mathrm{CH}_{3} \mathrm{COOH}\right), 447.3853(33 \%$, $\left.\mathrm{M}^{+}+1\right), 61.0251\left(1 \%, \mathrm{CH}_{3} \mathrm{COOH}+1\right)$.

4.3.3. $2 \alpha$-Hydroxycholestane-3 $\alpha$-yl acetate (3a). To a solution of cholestane- $2 \alpha, 3 \alpha$-diol $(\mathbf{3}, 40 \mathrm{mg}, 0.1 \mathrm{mmol})$ in toluene $(8 \mathrm{ml})$, vinyl acetate $(1 \mathrm{ml})$ and Novozym 435 $(80 \mathrm{mg}$ ) were added and the reaction mixture was shaken for 2 days, under the conditions described above. After usual work-up and purification by flash chromatography, $2 \alpha$-hydroxycholestane- $3 \alpha$-yl acetate was recovered (3a, $33 \mathrm{mg}, 75 \%$ ) and crystallized from methanol, $\mathrm{mp} 163-164{ }^{\circ} \mathrm{C}$.

Selected data: ${ }^{1} \mathrm{H}$ NMR $\left(\mathrm{CDCl}_{3}\right) \delta: 0.65\left(3 \mathrm{H}, \mathrm{s}, \mathrm{CH}_{3}-18\right)$, $0.82\left(3 \mathrm{H}, \mathrm{s}, \mathrm{CH}_{3}-19\right), 0.87\left(6 \mathrm{H}\right.$, two d, $J=6.5 \mathrm{~Hz}, \mathrm{CH}_{3}-26$ and $\left.\mathrm{CH}_{3}-27\right), 0.90\left(3 \mathrm{H}, \mathrm{d}, J=6.5 \mathrm{~Hz}, \mathrm{CH}_{3}-21\right), 2.12(3 \mathrm{H}, \mathrm{s}$, $\left.\mathrm{CH}_{3} \mathrm{CO}\right) 3.84(1 \mathrm{H}, \mathrm{dt}, J=4.2,11.4 \mathrm{~Hz}, \mathrm{H}-2 \beta), 5.12(1 \mathrm{H}, \mathrm{br}$ $\mathrm{q}, J=2.6 \mathrm{~Hz}, \mathrm{H}-3 \beta) .{ }^{13} \mathrm{C}$ NMR $\delta: 171.58,73.03,68.11$, $56.33,56.23,54.14,42.57,41.70,39.88,39.47,39.29$, $36.74,36.13,35.78,34.71,32.21,31.77,28.23,27.99$, $27.45,24.16,23.83,22.81,22.54,21.38,20.89,18.63$, 12.55, 12.04. FTIR (ATR): $\nu_{\max } 1027.4,1259.8,1714.7$, $2859.02952 .5,3516.3 \mathrm{~cm}^{-1}$. FI-MS $\mathrm{m} / \mathrm{z}=446.3828$ $\left(100 \%, \quad \mathrm{M}^{+}\right), \quad 386.3293 \quad\left(91 \%, \quad \mathrm{M}^{+}-\mathrm{CH}_{3} \mathrm{COOH}\right)$, $447.3842\left(29 \%, \mathrm{M}^{+}+1\right), 387.3349\left(23 \%, \mathrm{M}^{+}+1-\right.$ $\left.\mathrm{CH}_{3} \mathrm{COOH}\right)$.

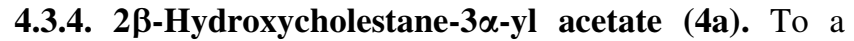
solution of cholestane-2 $\beta, 3 \alpha$-diol $(4,50 \mathrm{mg}, 0.124 \mathrm{mmol})$ in toluene $(10 \mathrm{ml})$, vinyl acetate $(1 \mathrm{ml})$ and Novozym 435 $(80 \mathrm{mg}$ ) were added and the reaction mixture was shaken for 3 days, under the conditions described above. After usual work-up and purification by flash chromatography, $2 \beta$-hydroxycholestane- $3 \alpha$-yl acetate was recovered as a single product $(\mathbf{4 a}, 47.6 \mathrm{mg}, 86 \%)$, $\mathrm{mp} 110-111^{\circ} \mathrm{C}$ (lit. ${ }^{1 \mathrm{~b}}$ $\left.106-107^{\circ} \mathrm{C}\right)$.

Selected data: ${ }^{1} \mathrm{H}$ NMR $\left(\mathrm{CDCl}_{3}\right) \delta: 0.65\left(3 \mathrm{H}, \mathrm{s}, \mathrm{CH}_{3}-18\right)$, $0.86\left(6 \mathrm{H}\right.$, two d, $J=6.6 \mathrm{~Hz}, \mathrm{CH}_{3}-26$ and $\left.\mathrm{CH}_{3}-27\right), 0.90(3 \mathrm{H}$, d, $\left.J=6.5 \mathrm{~Hz}, \mathrm{CH}_{3}-21\right), 0.99\left(3 \mathrm{H}, \mathrm{s}, \mathrm{CH}_{3}-19\right), 2.07(3 \mathrm{H}, \mathrm{s}$,

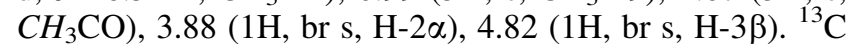
NMR $\delta: 170.52,72.92,68.65,56.43,56.25,54.97,42.58$, $40.46,39.99,39.89,39.46,36.13,35.77,35.34,34.81$, $31.85,28.66,28.21,27.97,24.11,23.83,22.80,22.53$, 21.40, 20.81, 18.62, 14.18, 12.06. FTIR (ATR): $\nu_{\max } 1033.1$, $1261.2,1714.2,2860.1-2953.8,3500.3 \mathrm{~cm}^{-1}$.

4.3.5. 3 $\alpha$-Hydroxycholestane-2 $\beta$-yl acetate (4b). To a solution of cholestane-2 $\beta, 3 \alpha$-diol $(\mathbf{4}, 50 \mathrm{mg}, 0.124 \mathrm{mmol})$ in toluene $(9 \mathrm{ml})$, vinyl acetate $(1 \mathrm{ml})$ and lipase PS $(200 \mathrm{mg})$ were added and the reaction mixture was shaken for 3 days, under the conditions described above. After usual work-up and purification by flash chromatography, $3 \alpha$-hydroxycholestane-2 $\beta$-yl acetate was recovered as a single product (4b, $37 \mathrm{mg}, 67 \%$ ), mp $115.7-116.2^{\circ} \mathrm{C}$ (lit. $85-86^{1 \mathrm{~b}}$ and $\left.113^{27}{ }^{\circ} \mathrm{C}\right)$.

Selected data: ${ }^{1} \mathrm{H}$ NMR $\left(\mathrm{CDCl}_{3}\right) \delta$ : $0.64\left(3 \mathrm{H}, \mathrm{s}, \mathrm{CH}_{3}-18\right)$, $0.86\left(6 \mathrm{H}\right.$, two d, $J=6.6 \mathrm{~Hz}, \mathrm{CH}_{3}-26$ and $\left.\mathrm{CH}_{3}-27\right), 0.89(3 \mathrm{H}$, $\left.\mathrm{d}, J=5.3 \mathrm{~Hz}, \mathrm{CH}_{3}-21\right), 0.90\left(3 \mathrm{H}, \mathrm{s}, \mathrm{CH}_{3}-19\right), 2.04(3 \mathrm{H}, \mathrm{s}$, $\left.\mathrm{CH}_{3} \mathrm{CO}\right), 3.84(1 \mathrm{H}$, br q, $J=2.3 \mathrm{~Hz}, \mathrm{H}-3 \beta), 4.87(1 \mathrm{H}$, br q, $\mathrm{H}-2 \alpha) .{ }^{13} \mathrm{C}$ NMR $\delta: 170.30,73.15,67.59,56.35,56.17$, $54.85,42.55,39.92,39.48,38.52,37.10,36.12,35.77,35.56$ $34.94,31.84,31.74,28.19,28.11,27.99,24.12,23.81$, $22.80,22.54,21.44,20.20,18.63,13.64,12.06$. FTIR (ATR): $\nu_{\max } 1034.5,1263.2,1716.4,2862.8-2928.4$, $3481.8 \mathrm{~cm}^{-1}$.

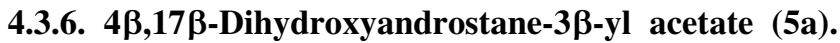
To a solution of androstane- $3 \beta, 4 \beta, 17 \beta$-triol $(\mathbf{5}, 35 \mathrm{mg}$, $0.114 \mathrm{mmol})$ in toluene $(5 \mathrm{ml})$, THF $(5 \mathrm{ml})$ and vinyl acetate $(1 \mathrm{ml})$, Candida rugosa lipase $(100 \mathrm{mg})$ was added and the reaction mixture was shaken for 3 days, under the conditions described above. After usual work-up and purification by flash chromatography (petroleum ether/ethyl acetate 2:1), $4 \beta, 17 \beta$-dihydroxyandrostan-3 $\beta$-yl acetate was recovered (5a, $29.3 \mathrm{mg}, 74 \%$ ).

Selected data: ${ }^{1} \mathrm{H}$ NMR $\left(\mathrm{CDCl}_{3}\right) \delta: 0.73\left(3 \mathrm{H}, \mathrm{s}, \mathrm{CH}_{3}-18\right)$, $1.06\left(3 \mathrm{H}, \mathrm{s}, \mathrm{CH}_{3}-19\right), 2.09\left(3 \mathrm{H}, \mathrm{s}, \mathrm{CH}_{3} \mathrm{CO}\right), 3.63(1 \mathrm{H}, \mathrm{t}, J=$ $8.7 \mathrm{~Hz}, \mathrm{H}-17 \alpha), 3.83(1 \mathrm{H}$, br t, H- $4 \alpha), 4.72(1 \mathrm{H}, \mathrm{ddd}, J=$ $3.2,4.8,8.0 \mathrm{~Hz}, \mathrm{H}-3 \alpha) .{ }^{13} \mathrm{C}$ NMR $\delta: 170.27,81.87,75.53$, $72.88,55.29,50.98,48.71,42.93,36.85,36.54,35.61$, $35.44,31.82,30.45,25.55,23.34,22.13,21.34,20.11$, 14.71, 11.11. FTIR (ATR): $\nu_{\max } 1041.5,1258.2$, 1709.3, 2840.9-2943.0, 3442.0 and $3530.1 \mathrm{~cm}^{-1}$. FD-MS $m / z=351.2470\left(100 \%, \mathrm{M}^{+}+1\right), 290.2104\left(78 \%, \mathrm{M}^{+}-\right.$ $\left.\mathrm{CH}_{3} \mathrm{COOH}\right), 350.2468\left(37 \%, \mathrm{M}^{+}\right)$.

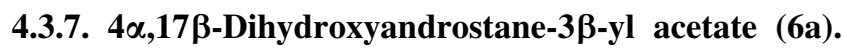
To a solution of androstane- $3 \beta, 4 \alpha, 17 \beta$-triol $(\mathbf{6}, 30 \mathrm{mg}$, $0.1 \mathrm{mmol})$ in acetone $(6 \mathrm{ml})$, THF $(3 \mathrm{ml})$ and vinyl acetate $(1 \mathrm{ml})$, Chromobacterium viscosum lipase $(200 \mathrm{mg})$ was added and the reaction mixture was shaken for 3 days, under the conditions described above. After usual work-up and purification by flash chromatography, $4 \alpha, 17 \beta$-dihydroxyandrostan-3 $\beta$-yl acetate was recovered (6a, $20.2 \mathrm{mg}, 60 \%$ ), and crystallized from methanol, $\mathrm{mp} 182-184{ }^{\circ} \mathrm{C}$.

Selected data: ${ }^{1} \mathrm{H}$ NMR $\left(\mathrm{CDCl}_{3}\right) \delta: 0.73\left(3 \mathrm{H}, \mathrm{s}, \mathrm{CH}_{3}-18\right)$, $0.86\left(3 \mathrm{H}, \mathrm{s}, \mathrm{CH}_{3}-19\right), 2.09\left(3 \mathrm{H}, \mathrm{s}, \mathrm{CH}_{3} \mathrm{CO}\right), 3.46(1 \mathrm{H}, \mathrm{t}, J=$ $9.5 \mathrm{~Hz}, \mathrm{H}-4 \beta), 3.64(1 \mathrm{H}, \mathrm{t}, J=8.5 \mathrm{~Hz}, \mathrm{H}-17 \alpha), 4.58(1 \mathrm{H}$, ddd, $J=5.4,9.2,11.6 \mathrm{~Hz}, \mathrm{H}-3 \alpha) .{ }^{13} \mathrm{C}$ NMR $\delta: 171.51$, $81.85,79.23,72.48,54.32,51.29,50.83,42.88,36.58$, $36.01,35.05,31.00,30.50,25.62,23.32,22.48,21.37$, $20.54,15.26,13.51,11.11$. FTIR (ATR): $\nu_{\max } 1035.6$, 1262.2, 1707.7, 2841.6-2940.9, 3443.3 and $3522.3 \mathrm{~cm}^{-1}$. FI-MS $m / z=290.2061 \quad\left(100 \%, \quad \mathbf{M}^{+}-\mathrm{CH}_{3} \mathrm{COOH}\right)$, $350.2541\left(39 \%, \mathrm{M}^{+}\right), \quad 291.2042\left(12 \%, \mathrm{M}^{+}+1-\right.$ $\left.\mathrm{CH}_{3} \mathrm{COOH}\right)$.

4.3.8. $3 \alpha, 17 \beta$-Dihydroxyandrostan- $4 \alpha$-yl acetate (7a). To a solution of $3 \alpha, 4 \alpha, 17 \beta$-trihydroxyandrostane (7, $118 \mathrm{mg}, 0.38 \mathrm{mmol})$ in acetone $(18 \mathrm{ml})$, THF $(4 \mathrm{ml})$ and vinyl acetate $(2 \mathrm{ml})$, lipase PS $(500 \mathrm{mg})$ was added and the reaction mixture was shaken for 4 days, under the conditions described above. After usual work-up and purification by 
flash chromatography, $3 \alpha, 17 \beta$-dihydroxyandrostan- $4 \alpha$-yl acetate was recovered (7a, $102.3 \mathrm{mg}, 76 \%)$ as a white powder.

Selected data: ${ }^{1} \mathrm{H}$ NMR $\left(\mathrm{CDCl}_{3}\right) \delta: 0.72\left(3 \mathrm{H}, \mathrm{s}, \mathrm{CH}_{3}-18\right)$, 0.87 (3H, s, $\left.\mathrm{CH}_{3}-19\right), 2.09$ (3H, s, $\left.\mathrm{CH}_{3} \mathrm{CO}\right), 3.64$ (1H, t, $J=$ $8.5 \mathrm{~Hz}, \mathrm{H}-17 \alpha), 4.01$ (1H, q, $J=2.9,2.7 \mathrm{~Hz}, \mathrm{H}-3 \beta) .4 .85$ $(1 \mathrm{H}, \mathrm{dd}, J=11.8,2.9 \mathrm{~Hz}, \mathrm{H}-4 \beta) .{ }^{13} \mathrm{C}$ NMR $\delta: 171.24,82.76$, $75.20,67.58,54.11,50.67,42.83,42.48,37.68,36.80$, $34.79,31.14,30.84,27.48,26.75,23.41,22.42,21.13$, 20.27, 12.82, 11.51. FTIR (ATR): $\nu_{\max } 1039.2,1265.1$, $1710.7,2841.6,3445.7$ and $3528.1 \mathrm{~cm}^{-1}$. FI-MS $\mathrm{m} / z=$ $308.2328\left(100 \%, \mathrm{M}^{+}+1-\mathrm{CH}_{3} \mathrm{CO}\right), 290.2052(71 \%$, $\left.\mathrm{M}^{+}-\mathrm{CH}_{3} \mathrm{COOH}\right), 350.2441\left(62 \%, \mathrm{M}^{+}\right), 332.2306(26 \%$, $\left.\mathrm{M}^{+}-\mathrm{H}_{2} \mathrm{O}\right), 351.2468\left(12 \%, \mathrm{M}^{+}+1\right)$.

4.3.9. $4 \alpha$-Hydroxycholestane-3 $\beta$-yl acetate (9a). To a solution of cholestane-3 $\beta, 4 \alpha$-diol $(\mathbf{9}, 50 \mathrm{mg}, 0.124 \mathrm{mmol})$ in acetone $(9 \mathrm{ml})$, vinyl acetate $(1 \mathrm{ml})$ and Chromobacterium viscosum lipase $(500 \mathrm{mg})$ were added and the reaction mixture was shaken under the conditions described above for 6 days. The usual work-up and flash chromatography yielded $4 \alpha$-hydroxycholestane-3 $\beta$-yl acetate (9a, $42.3 \mathrm{mg}$, $76 \%$ ), mp $169-170{ }^{\circ} \mathrm{C}$.

Selected data: ${ }^{1} \mathrm{H}$ NMR $\left(\mathrm{CDCl}_{3}\right) \delta: 0.65\left(3 \mathrm{H}, \mathrm{s}, \mathrm{CH}_{3}-18\right)$, 0.84-0.91 (12H, $\left.\mathrm{CH}_{3}-19, \mathrm{CH}_{3}-21, \mathrm{CH}_{3}-26, \mathrm{CH}_{3}-27\right), 2.08$ $\left(3 \mathrm{H}, \mathrm{s}, \mathrm{CH}_{3} \mathrm{CO}\right), 3.45(1 \mathrm{H}, \mathrm{t}, J=9.7 \mathrm{~Hz}, \mathrm{H}-4 \beta), 4.57(1 \mathrm{H}$, ddd, $J=5.3,9.1,11.5 \mathrm{~Hz}, \mathrm{H}-3 \alpha) .{ }^{13} \mathrm{C}$ NMR $\delta: 171.49$, $79.24,72.47,56.30,56.18,54.21,51.23,42.45,39.85$, $39.46,36.83,36.10,35.96,35.76,34.97,31.44,28.22$, $27.97,25.65,24.12,23.80,22.79,22.60,21.53,21.36$, 20.94, 18.61, 13.46, 12.01. FTIR (ATR): $\nu_{\max } 1036.6$, $1263.2,1715.4,2860.9-2930.2,3549.3 \mathrm{~cm}^{-1}$. FI-MS $m / z=$ $386.3400\left(100 \%, \mathrm{M}^{+}-\mathrm{CH}_{3} \mathrm{COOH}\right), 446.3787\left(33 \%, \mathrm{M}^{+}\right)$, $387.3417\left(27 \%, \mathrm{M}^{+}+1-\mathrm{CH}_{3} \mathrm{COOH}\right), 447.3893(13 \%$, $\left.\mathrm{M}^{+}+1\right)$.

\section{Acknowledgements}

Thanks are due to Fundação para a Ciência e Tecnologia (FCT) through POCTI (FEDER) and to the CNR-GRICES bilateral exchange program (2003-2004) for financial support. M. M. C. S. wishes to thank Fundação Calouste Gulbenkian for a Ph.D. grant.

\section{References and notes}

1. (a) Rudi, A.; Yosief, T.; Loya, S.; Hizi, A.; Schleyer, M.; Kashman, Y. J. Nat. Prod. 2001, 64, 1451-1453. (b) Garrido Santos, G. A.; Murray, A. P.; Pujol, C. A.; Damonte, E. B.; Maier, M. S. Steroids 2003, 68, 125-132. (c) Roccatagliata, A. J.; Maier, M. S.; Seldes, A. M. J. Nat. Prod. 1998, 61, 370-374.

2. Aoki, S.; Naka, Y.; Itoh, T.; Furukawa, T.; Rachmat, R.; Akiyama, S.-I.; Kobayashi, M. Chem. Pharm. Bull. 2002, 50, 827-830.

3. (a) Higa, T.; Tanaka, J.; Tsukitani, Y.; Kikuchi, H. Chem. Lett. 1981, 11, 1647-1650. (b) Rao, C. B.; Ramana, K. V.; Rao,
D. V.; Fahy, E.; Faulkner, D. J. J. Nat. Prod. 1988, 51, 954-958.

4. (a) Mimaki, Y.; Kuroda, M.; Kameyama, A.; Yokosuka, A.; Sashida, Y. Phytochemistry 1998, 48, 1361-1369. (b) Mimaki, Y.; Kuroda, M.; Fukasawa, T.; Sashida, Y. Chem. Pharm. Bull. 1999, 47, 738-743. (c) Candra, E.; Matsunaga, K.; Fujiwara, H.; Mimaki, Y.; Kuroda, M.; Sashida, Y.; Ohizumi, Y. J. Pharm. Pharmacol. 2002, 54, 257-262.

5. Aoki, S.; Yoshioka, Y.; Miyamoto, Y.; Higushi, K.; Setiawan, A.; Murakami, N.; Chen, Z.-S.; Sumizawa, T.; Akiyama, S.-I.; Kobayashi, M. Tetrahedron Lett. 1998, 39, 6303-6306.

6. Tsukamoto, S.; Tatsuno, M.; van Soest, R. W. M.; Yokosawa, H.; Ohta, T. J. Nat. Prod. 2003, 66, 1181-1185.

7. Lønning, P. E.; Geisler, J.; Johannessen, D. C.; Gschwind, H.-P.; Waldmeier, F.; Schneider, W.; Galli, B.; Winkler, T.; Blum, W.; Kriemler, H.-P.; Miller, W. R.; Faigle, J. W. J. Steroid Biochem. Mol. Biol. 2001, 77, 39-47.

8. Rogers, L. L.; Zeng, L.; McLaughlin, J. L. J. Org. Chem. 1998, 63, 3781-3785.

9. (a) Burgoyne, D. L.; Andersen, R. J.; Allen, T. M. J. Org. Chem. 1992, 57, 525-528. (b) Bramley, A. M.; Langlands, J. M.; Jones, A. K.; Burgoyne, D. L.; Li, Y.; Andersen, R. J.; Salari, H. Br. J. Pharmacol. 1995, 115, 1433-1438.

10. Yoshida, M.; Murata, M.; Inaba, K.; Morisawa, M. Proc. Natl. Acad. Sci. 2002, 99(23), 14831-14836.

11. (a) Carrea, G.; Riva, S. Angew. Chem., Int. Ed. 2000, 39, 2226-2254. (b) Gotor, V. Org. Process Res. Dev. 2002, 6, 420-426. (c) Schulze, B.; Wubbolts, M. G. Curr. Opin. Biotechnol. 1999, 10, 609-615.

12. (a) Secundo, F.; Carrea, G.; De Amici, M.; Joppolo di Ventimiglia, S.; Dordick, J. S. Biotechnol. Bioeng. 2003, 81, 391-396. (b) Bortolini, O.; Medici, A.; Poli, S. Steroids 1997, 62, 564-577.

13. (a) Njar, V. C. O.; Caspi, E. Tetrahedron Lett. 1987, 28, 6549-6552. (b) Riva, S.; Bovara, R.; Ottolina, G.; Secundo, F.; Carrea, G. J. Org. Chem. 1989, 54, 3161-3164. (c) Ottolina, G.; Carrea, G.; Riva, S. Biocatalysis 1991, 5, 131-136. (d) Bertinotti, A.; Carrea, G.; Ottolina, G.; Riva, S. Tetrahedron 1994, 50, 13165-13172.

14. Riva, S.; Klibanov, A. M. J. Am. Chem. Soc. 1988, 110, 3291-3295.

15. (a) Ferraboschi, P.; Molatore, A.; Verza, E.; Santaniello, E. Tetrahedron: Asymmetry 1996, 7, 1551-1554. (b) Ferraboschi, P.; Reza-Elahi, S.; Verza, E.; Santaniello, E. Tetrahedron: Asymmetry 1998, 9, 2193-2196.

16. Cruz Silva, M. M.; Sá e Melo, M. L.; Parolin, M.; Tessaro, D.; Riva, S.; Danieli, B. Tetrahedron: Asymmetry 2004, 15, 21-27.

17. Ferraboschi, P.; Colombo, D.; Reza-Elahi, S. Tetrahedron: Asymmetry 2002, 13, 2583-2586.

18. Cruz Silva, M. M.; Riva, S.; Sá e Melo, M. L. Tetrahedron: Asymmetry 2004, 15, 1173-1179.

19. Danieli, B.; Lesma, G.; Luisetti, M.; Riva, S. Tetrahedron 1997, 53, 5855-5862.

20. (a) Woodward, R. B.; Brutcher, F. V. J. Am. Chem. Soc. 1958 , 80, 209-211. (b) Horiuchi, C. A.; Satoh, J. Y. Chem. Lett. 1988, 7, 1209-1210.

21. (a) Henbest, H. B.; Smith, M. J. Chem. Soc. 1957, 926-927. (b) Davey, C. W.; McGinnis, E. L.; McKeown, J. M.; Meakins, G. D.; Pemberton, M. W.; Young, R. N. J. Chem. Soc. (C). 1968, 2674-2682.

22. (a) Boul, A. D.; Fairweather, P. M.; Hall, J. M.; Meakins, G. D. J. Chem. Soc. (C) 1971, 1199-1202. (b) Shoppee, C. W.; 
Jones, D. N.; Summers, G. H. R. J. Chem. Soc. 1957, 3100-3107.

23. (a) Nakata, H. Bull. Chem. Soc. Jpn. 1965, 38, 378-380. (b) Hanson, J. R.; Hitchcock, P. B.; Liman, M. D.; Nagaratnam, S. J. Chem. Soc. Perkin Trans. 1 1995, 2183-2187. (c) Campos Neves, A. S.; Sá e Melo, M. L.; Moreno, M. J. S. M.; Tavares da Silva, E. J.; Salvador, J. A. R.; Costa, S. P.; Martins, R. M. L. M. Tetrahedron 1999, 55, 3255-3264.

24. MacDonald, I. A. J. Chromatogr. 1977, 136, 348.

25. D’Onofrio, F.; Scettri, A. Synthesis 1985, 1159-1161.

26. Glotter, E.; Schwartz, A. J. Chem. Soc., Perkin Trans. 1 1976, $1660-1662$.
27. Williamson, K. L.; Johnson, W. S. J. Org. Chem. 1961, 26, 4563-4569.

28. (a) Rowland, A. T.; Nace, H. R. J. Am. Chem. Soc. 1960, 82, 2833-2836. (b) Fieser, L. F.; Rajagopalan, S. J. J. Am. Chem. Soc. 1949, 71, 3938-3941.

29. Salvador, J. A. R.; Sá e Melo, M. L.; Campos Neves, A. S. Tetrahedron Lett. 1993, 34, 357-360.

30. Tömörkény, E.; Tóth, G.; Horváth, G.; Büki, K. G. Acta Chim. Acad. Sci. Hung. 1975, 87, 409-418.

31. Fieser, L. F.; Stevenson, R. J. Am. Chem. Soc. 1954, 76, 1728-1733. 